"Towards inclusive education for environmental sustainability at a University of Technology"

\begin{tabular}{|c|c|c|}
\hline AUTHORS & Ivan Govender & \\
\hline ARTICLE INFO & $\begin{array}{l}\text { Ivan Govender (2016). Towards } \\
\text { sustainability at a University of T } \\
\text { 84. doi:10.21511/ee.07(4).2016. }\end{array}$ & $\begin{array}{l}\text { n for environmental } \\
\text { onmental Economics, 7(4), 78- }\end{array}$ \\
\hline DOI & http://dx.doi.org/10.21511/ee.07 & \\
\hline RELEASED ON & Friday, 09 December 2016 & \\
\hline JOURNAL & "Environmental Economics" & \\
\hline FOUNDER & LLC “Consulting Publishing Cor & "erspectives" \\
\hline & & $\begin{array}{l}\text { ニ-: } \\
\text { Z:- }\end{array}$ \\
\hline NUMBER OF REFERENCES & NUMBER OF FIGURES & NUMBER OF TABLES \\
\hline
\end{tabular}

(C) The author(s) 2021. This publication is an open access article. 
Ivan Govender (South Africa)

\title{
Towards inclusive education for environmental sustainability at a University of Technology
}

\begin{abstract}
The purpose of the study is to evaluate the efforts of Durban University of Technology to provide a more inclusive education for the transition towards an economic and sustainable environment. The paper is centred on assessing the current general education program implemented by Durban University of Technology by exploring the general education environmental knowledge domains. In 2009, the Durban University of Technology Senate accepted the general education guidelines for curriculum renewal and stipulated the aims of general education as building a studentcenteredness experience, preparing students for the complex and changing globalized environment and to cultivate responsible citizenship. Documentary analysis was undertaken to assess the graduate attributes and its incorporation into the general education modules. The general education policy documents, thematic clustering, module descriptors and study guides were inspected to establish the scope of the knowledge that would aid students to engage in a transitional and transformational world. The study findings highlighted that while the general education modules related to environmental sustainability, there was little evidence of the green economy being included in the general education curricula. DUT needs to progress towards becoming a sustainable university to enrich the students' experiences in education in sustainable development (ESD) through committed leadership, being lecturer focused and developing a participatory monitoring and evaluation system for ESD. The study is of value to higher education and governmental institutions engaged in transformative learning and education policy development in environmental management and green economy.
\end{abstract}

Keywords: green economy, general education, sustainable development, evaluation.

JEL Classification: Q56, Q01.

\section{Introduction}

Climate change and environmental degradation is a consequence of unsustainable business and consumption patterns that present critical global and local challenges for the current and future generations. Therefore, the key challenge for the higher education sector is to provide well-prepared graduates who could engage with the complex social, political and environmental challenges facing society. Since higher education institutions operate within the broader economy, they are also affected by the current low economic growth, political instability, high unemployment and huge income inequalities in South Africa. In addition, there is a demand for higher education institutions to transform by placing greater emphasis on massification, accessibility, affordability, increased research output and sustainable development curricula while being constrained by inadequate student funding, legitimacy of higher education and policy development and implementation. Collectively, the above factors create a complex environment with no evidence of key stakeholders dealing with these issues in a strategic and sustainable manner that could minimize the adverse effects of the above issues.

(C) Ivan Govender, 2016.

Ivan Govender, Dr., Senior Lecturer, Economics and Management, Department of Entrepreneurial Studies and Management, Durban University of Technology, South Africa.
To partly meet this challenge, Durban University of Technology introduced general education through its recurriculum process of its program offerings. However, a globalized system requires graduates to be skilled to deal with issues of preserving the environment, monitoring of natural resource consumption and balancing economic growth and sustaining both the current and future societies' needs. It is, therefore, critical to educate both the undergraduate and postgraduate students in the green economy for sustainable development. This study evaluates the extent to which the current general education program delivers on the skills and competencies for developing the green economy.

\section{Theoretical framework}

1.1. Education for sustainable development. In 1997, UNESCO has emphasized that education is the most effective means that society could use for dealing with the challenges of the future by education for sustainable development (ESD) through transformative action. According to The United Nations Decade of Education for Sustainable Development (DESD, p. 104), the key processes that underpin ESD include multi-stakeholder and intercultural collaborations and dialogues, a systemic approach to curriculum development, teaching and learning, and active and participatory learning. It must be noted that the contextual factors for sustainable development, namely, population growth, energy, resource availability and consumption levels, food production yield and growth in pollution create a "wicked problem" requiring creative and innovative methods to deal with the challenges. 
Desha and Hargroves (2014, p. 4182) argue that despite the decade long focus on ESD, key professions still lack critical knowledge and skills to bring about sustainable solutions due to a lack of understanding of the complexity of capacity building challenges to support the current trends in innovation. Desha and Hargroves (2014, p. 4194) further propose that greater effort be made to investigate, document and support the design of curriculum renewal strategies aimed at sustainable development. To overcome these challenges, Fong (2013, p. 13) suggests that universities prepare students to be contributing citizens and leaders in a global society through an interpenetration of town and gown, of classroom and the real world. This implies that all stakeholders need to acquaint themselves with the needs of society, the economy and the environment. Within these contexts, employers require graduates to possess contemporary management skills relevant to a complex business environment which could only be achieved if universities implement teaching, learning and assessment strategies to accommodate the complexity and rapid rate of change.

\subsection{Durban University of Technology and} general education. Durban University of Technology (DUT) embarked on a curriculum renewal program that included the formalization of general education into the undergraduate programs and the development of graduate attributes. In 2009, the Durban University of Technology Senate accepted the general education guidelines for curriculum renewal and stipulated the aims of general education as building a student-centeredness experience, preparing students for the complex and changing globalized work environment and to cultivate responsible citizenship. Here, responsible citizenship also includes the preservation of the physical environment and natural resources. Included in this document are the graduate attributes that each graduate should inculcate, by participating in the general education program, to ensure he/she plays a meaningful role in society and to embrace life-long learning. While, the quality assurance of graduate attributes was considered as a means to monitor and evaluate the effectiveness of the general education program, Durban University of Technology has, yet, to complete a program to undertake such an evaluation.

General education was introduced, since the standard knowledge-based educational approaches to behavior change have a disappointing track record (Finger, 2010; Nolet, 2009; Stern, 2000). General education is defined as holistic and integrative approach to develop the graduate attributes and is grounded in the daily living experiences of students. The aims of general education at DUT are to build a student-centered educational experience embedded in the local context, to prepare students for an increasingly diverse and complex globalized work environment, and to cultivate an engaged and critical citizenry in the context of an emerging and fragile democracy in an ever changing world order (DUT, 2009). For DUT to be successful as a UOT and to achieve the above graduate attributes, it requires different strategies and innovative leadership and a "critical paradigm shift" across all its activities. Interestingly, DUT is the only university of technology that offers general education comprising $30 \%$ of the program content, so that the general education program achieves the outcomes of student-centeredness, engagement and responsible citizenship. The general education program was not, yet, fully implemented across all six faculties and in all programs at DUT. Since this article focuses on sustainable development, only the environmental sustainability theme would be explored in this study.

Bawa (2013, p. 38), in proposing a speculative integrative model for higher education in the province of Kwa-Zulu Natal, alluded to general education to be the cement of the proposal. The proposal envisaged $50 \%$ of the undergraduate qualification to be general education which would enable the gap between poor high school and university education to be addressed, skills development to be integrated, to better manage the articulation of the various programs; to deepen and strengthen democracy and, finally, to develop university students as lifelong learners. Subjects to be taught include philosophy, mathematics, literature, writing courses, communication and technology that could enhance the value of the new graduate to prospective employers. However, the proposal seems not to adequately provide strategies to address the issues of the economy and its relations with environmental management. And the poor quality basic schooling which impacts on the preparedness of students entering universities. Nevertheless, the proposal further highlights the significance of general education to adequately prepare students in dealing with the sustainable development challenges.

The outcomes of general education are stipulated as intellectual and practical skills, innovative and creative initiatives, understanding and appreciation of diversity, social responsibility, personal development, and integrative learning strategies. To give effect to these outcomes, seven themes were identified for the purposes of developing modules, namely, environmental sustainability, history, politics, economics, and philosophy, languages, 
culture and society, work preparedness, entrepreneurship, personal development, and health and wellness. This paper will focus on environmental sustainability.

The Environmental Sustainability theme aims to bring students to an informed and ethically minded understanding of humans in the context of the life systems of the world. It requires that students develop a critical understanding of the consequences of human interaction with the environment, of the relationship between environmental factors and our economic, social and cultural life, and of the optimal ways of ensuring the sustainability of human and other life. Such concepts as 'development' and 'biodiversity' would be interrogated. Modules within this theme need to take both a local and global perspective and students are required to read widely and be able to communicate the links they trace between theory and lived experience. It must be noted that while the subject matter may not be fully addressed by the general education modules, it may be embedded in the programs.

To further promote ESD, it is proposed that the following modules may be developed under the environmental stability theme, namely, introduction to green chemistry, biofuels, biotechnology and society, my universe, sustainable development, global environmental issues, and food and security. For example, the purpose of the global environment general education module is to enable students to critically engage with social, economic and personal impacts on the local and global environment, but excludes highlighting the role of the global economy. The module descriptor stipulates the learning outcomes as the ability of the student to differentiate between various types of environmental pollution and its impact (social, economic and personal), describes the social, economic and environmental impact of human population growth, explains the consequences of climate change on human health, natural resources and biodiversity, and identifies the inter-relationships between sustainable development, social responsibility, economic development and environmental protection. It should be noted that the progression of general education at DUT is seen to be developmental and the institution do not have a formalized sustainable development policy. Under these circumstances, the module developers' efforts to create awareness of sustainable development should be acknowledged.

1.3. Graduate attributes. Graduate attributes are defined as the qualities, skills and understanding a university graduate should develop while at campus that impact on their ability to contribute to their society and profession (DUT, 2014, p. 4). An effective quality assurance framework is required to provide information of the students' achievements of the graduate attributes, as it affects employability, institutional image and the future student enrolments (DUT, 2014, p. 3).

General education at DUT requires innovative and high impact teaching and learning approaches including the use of technology, community engagement, service learning. Every DUT graduate should possess basic proficiency and competencies (including information literacy, communication, numeracy, technology applications), innovation (including entrepreneurship, leadership), social responsibility (ethics; diversity; critical and engaged citizenry), personal development (including self-awareness, self-directed and lifelong learning), and broad understanding of their chosen discipline and/or profession (including a professional approach to knowledge production, workplace adaptability). These attributes compare closely with the generic traditional attributes, but are not clearly aligned to the generic sustainability attributes (see below).

According to Murga-Menoyo (2014, p. 2982), generic traditional competencies include methodological skills, time management and learning skills, problem solving and decision making), technological skills (computer, machinery and information management), linguistic skills (written and verbal), individual and social capacities (express an ethical and social commitment) and systems thinking. However, the general competencies for sustainability include critical contextualization of knowledge, establishing interrelationships between social, economic and environmental problems, local and/or global; Sustainable use of resources and prevention of negative impacts on the natural and social environment, participation in community processes which promote sustainability, and application of ethical principles related to sustainability values in personal and professional behavior. The author further argues that there is a low proportion of higher education students that possess the specialized skills for a green economy. While it may be argued that these skills do not belong to the basket of general education modules offered, it is the responsibility of the institution to ensure that the relevant disciplines offer such specialized skills.

1.4. Teaching and learning theories. According to Glynn, Aultman and Owens (2005, p. 151), contemporary general education should encourage the students to habituate their thinking so that they could understand critical issues, learn and act independently both inside and outside their disciplines and provide the fundamental skills that would make the student successful at university and 
in his/her chosen career. To ensure success, the following motivational constructs could be effected, namely, students' traits and state, students beliefs and the Pygmalion effect. The extent the above constructs influence student learning depends on which of the behavioral, humanistic, cognitive and social orientations are used by researchers. Another requirement of general education programs is that it should focus on alignment and cohesion, on learning competencies rather than disciplined knowledge and interdisciplinary engagements that enhances the integration of knowledge from different disciplines (Smith, Brunton and Kohen, 2001). The above constructs are critical, as the majority of the students attending DUT are from the previously disadvantaged black communities that experiences poor quality basic education.

To narrow the gap between what is being taught and the requirements of the green economy, Desha and Hargroves (2014, p. 4185) propose a dual track curriculum renewal program for both undergraduates and postgraduates by responding to the needs of society. Firstly, the rate of economic growth is reduced to alleviate pressure on the environment. The universities should provide the necessary skills to maintain the economic growth while reducing the pressures on the environment. An example would be to reduce the carbon dioxide footprint by using renewable energy sources while maintaining the economic growth. In the next phase, the environmental quality is enhanced while maintaining the economic growth. Here, universities need to provide the additional skills to ensure that the students could engage in further enhancing the quality of the environment. It seems this approach requires the university to be strategic in its course offerings, teaching and learning and research in sustainable development which could require more resources. Currently, the higher education sector in South Africa is experiencing demands for transformation and to make higher education more accessible to the masses which could place constraints on the universities resources.

1.5. Participatory monitoring and evaluation. Monitoring is the collection of data to assess the performance against set standards and to take timeous corrective action if required, whereas evaluation measures the value or merit of an intervention and could be either summative and/or formative. Participatory monitoring and evaluation engages key stakeholders in the planning, organizing, decision making and problem solving processes to improve the current program and /or gain new knowledge. An ESD monitoring and evaluation framework assists in ensuring the relevance and effectiveness of ESD efforts, guide planning and reorientation of the ESD programs, increase understanding and knowledge building (Tilbury 2007, p. 20). The effectiveness of an evaluation system is enhanced by quality indicators that show how well a system is working and locate the issues that need attention. In addition, asking key evaluation questions relating to the achievement of the set outcomes, cost-benefit analysis, lessons learned and stakeholder engagement would enhance future implementation and success of education in sustainable development.

\section{Themes emerging from literature}

2.1. Leadership and sustainable universities. Leadership is critical for the support and commitment to ensure ESD is included in every activity. The more leadership is exercised across the institution, collaborations and partnerships should strengthen working with other disciplines (Stoddard, Hewitt and Danforth, 1997) citing Goodlad, 1993). A university that is serious about ESD should enrich the students' campus life through good green economy practices, programs and support mechanisms. A collective and collaborative approach is required for the development of green campus, green curriculum, green research, green community and green culture. According to Clugston and Clader (1999, p. 3), the critical dimensions of a university committed to ESD include:

- Written statements, namely, the vision, mission, learning outcomes and public relations material would highlight the concern for sustainability.

- Concepts of sustainability are included in all disciplines, in liberal arts, professional education requirements and research. The role the institution plays in its social and ecological system providing an opportunity for students learning. Here, the use of water, energy and waste management; institutions views and treatment of employees becomes more relevant as a learning intervention for students.

- Knowledge of sustainability is critical for teaching and research - placements, rewards and staff development opportunities are provided for those with SD knowledge.

- Operational activities should formulate the institutions ecological footprint through evidence based policy and decision making.

- Institutional support and campus life should emphasise sustainability development events.

- Engagement in outreach and forming partners both locally and internationally is critical to enhance both teaching and learning about the green economy. 
Clearly, ESD requires a systems approach and systems thinking to be used by the institutional leadership to ensure that all its activities are organized and implemented within the green economy principles. In addition, a quality assurance system for general education and the monitoring and evaluation of the achievement of the graduate attributes need to be considered (DUT, 2014, p. 15).

2.2. Lecturer-centredness. Tagg and Barr (1995, p. 13) noted that the colleges were transforming from an institution that provides instruction to one that exists to provide learning. One of the learning paradigm outcomes is that "each graduating class learns more than the previous graduating class". This implies that the institution, learners and the lecturer has to learn how to produce more learning, thus, creating a culture of a learning organization. To this end, the continuous professional development of staff in teaching, learning and assessing general education and sustainable development modules with ESD competencies and skills is essential. Critical thinking skills is essential and course offerings should include topics such as globalization and sustainable development, environmental philosophy, nature writing, land ethics and sustainable agriculture, urban ecology and social justice, population, women and development, sustainable production and consumption (Clugston and Clader, 1999, p. 3). Lecturers need to be sufficiently motivated, knowledgeable and regularly capacitated in the above knowledge domains. Cleary, ESD would not fully achieve its desired outcomes if administrative and support staff are excluded from its programs, as they support the academic activities. Therefore, both administrative and support staff should also be capacitated in the relevant sustainable development issues. Therefore, for ESD to be successful, both academics and support staff should be empowered to use mechanisms that enhance the teaching and promotion of the green economy.

2.3. Interdisciplinary approaches to teaching and research. Education for the green economy requires a paradigm shift in both teaching, learning and assessment approaches which could include systems thinking and interdisciplinary thinking (Cartese, 1992; Buckingham-Hattfield, 1996). However, not much success has been achieved through interdisciplinary approaches, as the institution eventually gravitates towards the entrenched knowledge of single disciplines (Warburton, 2003). This could be attributed to the complexities of managing a faculty with diverse specialists teaching and researching together. To fully understand the interdependencies and interrelationships between the different disciplines through comparative and synthetic thinking, deep learning is critical. Warburton (2003, p. 45) views deep learning as the consideration of underlying meaning through the use of analytic skills, cross-referencing, imaginative reconstruction and independent thinking whereas surface learning emphasizes rote learning and simple description. Factors affecting deep learning include the students' engagement with the topic, the intention to understand rather than pass an assessment. More importantly, deep learning is required for the attainment of the four competencies for a sustainable economy, namely, the traditional general competencies, social behaviors and styles, competencies for the technical green jobs, and competencies for continuous professional development, as processes and technologies advance (Murga-Menoyo, 2014, p. 2977).

\section{Discussion}

Shay (2016, p. 3) argues that the South African undergraduate curriculum is no longer fit for its purpose as the profile of students accessing higher education and the world of work in a globalized context keeps changing. Another challenge for higher education institutions is the relevance of the curriculum since specific knowledge domains of particular disciplines may not be sufficient to address the real world "wicked problems" created by the sustainable development contexts. In order to achieve the green economy outcomes, key stakeholders, such as government, businesses, educational institutions, NGO's should ensure their policies, programs and projects are managed with the required level of technical and conceptual skills and technological advancements. Therefore, transiting towards a green economy should make education at all levels central to the sustainable development and green economy initiatives. This requires commitment from the leaders to develop sustainable universities through systems approach and deep thinking to positively influence teaching, learning and assessment strategies, promote.

While the above efforts should assist the progress towards ESD, the analysis of the environmental sustainability theme module descriptors does not clearly identify the role of society and the global economy, and the transition to the green economy, which is critical for the students' awareness of his/her role in society and in greening the daily activities. In this regard, Nhlamo (2014) concurs that the higher education sector has, yet, to fully engage in preparing students for the green economy, since the sector remains grounded in old curricula, thereby starving organisations of much-needed, specialized green economy skills. It seems that there is a gap in what the universities teach the students and the requirements of the employers of the new graduates. 
Curricula should, therefore, also address the adaptation and mitigation agenda requirement for any green economy transition and the lack of reflective skills of the higher education sector in this country is well documented. One way to overcome this challenge is to practice interdisciplinarity in teaching, learning and research by transforming the "silo" mentality to developing a collaborative enterprise.

To achieve the above, teaching and learning for the green economy requires management, educators and learners to adopt different values, attitudes and behaviors to transition towards green economy. However, the current re-curriculum program needs to be transformative by including procedural effectiveness and social knowledge rather than focusing on declarative knowledge on how environmental systems work (Frisk and Larson, 2011, p. 2151). To give effect to the graduate attributes, behavioral change outcomes, sustainability discourses and educational pedagogy needs to be aligned and integrated for transformative action. While a student-centred approach for ESD is important, academics determine the curriculum, context and mode of facilitation for the attainment of the graduate attributes and sustainable development outcomes. This study argues that for successful ESD, more attention should be placed on the academics' professional development and motivation, making the institution more lecturer-centred.

Finally, participatory monitoring and evaluation for ESD is critical, as the current program offerings based on standard knowledge-based educational approaches to sustainable development are inadequate for achieving transformative action (Frisk and Larson, 2011 citing Finger, 2010; Nolet, 2009; Stern, 2000). Here, the impact of teaching and learning approaches, behavioral changes and effects greening the economy could be evaluated. This implies the involvement of key stakeholders to collectively make evidence based decisions and develop policies that would enhance the overall performance of the university in ESD.

\section{Conclusion}

Durban University of Technology has used the re-curriculum process to introduce general education into all of its undergraduate programs. While the development of general education modules and it implementation are work in progress, the basket of general education modules adequately represent the general competencies for sustainable development, thus, enhancing an inclusive education for sustainable development. However, there is little evidence of green economy skills and competencies being included in the environmental sustainability theme modules. The study has also found that leadership for creating a sustainable university; interdisciplinarity, lecturer centeredness and the higher education contextual environment is critical for ESD. Durban University of Technology should endeavor to establish itself as a sustainable university and develop a participatory monitoring and evaluation system for ESD.

\section{References}

1. Barr, R.B., Tagg, J. (1995). From Teaching to Learning - A New Paradigm for Undergraduate Education, Change, 27(6), pp. 13-25.

2. Bawa, A.C. (2013). Righting an inverted pyramid: Managing a perfect storm, Alternation, pp. 25-45.

3. Clugstan, R.M., Calder, W. (1999). Critical Dimensions of Sustainability in Higher Education. In Sustainability and University Life, W.L. Filho, (ed). Peter Lang Publishers.

4. Desha, C., Hargroves, K.C. (2014). A Peaking and Tailing Approach to Education and Curriculum Renewal for Sustainable Development, Sustainability, 6, pp. 4181-4199.

5. Down, L. (2006). Addressing the challenges of Mainstreaming Education for Sustainable Development in Higher Education, International Journal of Sustainability in Higher Education, 7(4), pp. 390-399.

6. Durban University of Technology. (2009). Curriculum renewal at DUT: General education Guidelines, Senate approved, 29 August 2012.

7. Durban University of Technology. (2014). A Position Paper: Conceptualising the Quality Assurance of Graduate Attributes at the Durban University of Technology, Senate Approved, 27 August 2014.

8. Fong, B. (2013). General Education: Connecting to issues of vital importance - for students, for society. AAC\&U Network for Academic Renewal, Boston MA.

9. Frisk, E., Larson, K.L. (2011). Education for Sustainability: Competencies and Practices for Transformative Action, Journal of Sustainable Education, Vol. 2, March 2011.

10. Glynn S.M., Aultman, L.P., Owens, A.M. (2005). Motivation to learn in general education programs, The Journal of General Education, 54(2), pp. 150-170.

11. Murga-Menoyo, M.A. (2014). Learning for a Sustainable Economy: Teaching of Green Competencies in the University, Sustainablity, 6, pp. 2974-2992.

12. Nhlamo, G. (2014). Green Economy Readiness in South Africa: A focus on the national sphere of government, University of South Africa, Exxaro Chair in Business and Climate Change Institute for Corporate Citizenship, Pretoria.

13. Shay, S. (2016). Decolonising the curriculum: its time for a strategy, The Conversation, 13 June 2016. 
14. Smith, V.R., Brunton, B.G., Kohen, A.I. (2001). General Education Reform: Thinking critically about substance and process, Journal of General Education, 50(2), pp. 86-101.

15. Stoddard, K., Hewitt, M., Danforth, S. (1997). The BRIDGE Project: Bridging the Gap Between University and Schools, Journal of Learning Disabilities, 30(4), pp. 408-413.

16. Tilbury, D. (2007). Monitoring and Evaluation during the UN Decade of Education for Sustainable Development, Journal of Education for Sustainable Development, 1(2), pp. 239-254.

17. Tilbury, D. (2011). An Expert Review of Processes and Learning: UNESCO. Education for Sustainable Development.

18. Warburton, K. (2003). Deep Learning and education for sustainability, International Journal of Sustainability in Higher Education, 4(1), pp. 44-56. 